\title{
Microduplication with Autoimmune Inflammatory Arthritis
}

Yap TS ${ }^{1}$, Adib $\mathbf{N}^{2,3,4}$ and Coman $\mathbf{D}^{1,3,4,5^{*}}$

${ }^{1}$ Department of Metabolic Medicine, The Lady Cilento Children's Hospital, Brisbane, Australia

2Department of Rheumatology, The Lady Cilento Children's Hospital, Brisbane, Australia

${ }^{3}$ Uniting Care Health Clinical School, The Wesley Hospital, Brisbane, Australia

${ }^{4}$ School of Medicine, The University of Queensland, Brisbane Australia

${ }^{5}$ School of Medicine, Griffith University, Gold Coast, Australia

"Corresponding author: David Coman, MBBS, MPhil, FRACP, Department of Neuroscience, Lady Cilento Children's Hospital, Stanley Street, South Brisbane, 4101 Queensland, Australia, Tel: +61730681111; Fax: +617 30684079; E-mail: david.coman@health.qld.gov.au

Received date: November 24, 2014, Accepted date: January 30, 2015, Published date: February 06, 2015

Copyright: (c) 2015 Yap TS, et al. This is an open-access article distributed under the terms of the Creative Commons Attribution License, which permits unrestricted use, distribution, and reproduction in any medium, provided the original author and source are credited.

\begin{abstract}
We describe a third case with clinical characterization due to 7 p22.1 microduplication in an 8 year old female diagnosed concurrently with autoimmune Systemic Lupus Erythematosus. We propose that 7p22.1 microduplication can be associated with autoimmune arthritis as consequent copy number variations in autoimmune gene susceptibility loci within chromosome 7. Our case highlights the need for joint surveillance in children with microduplication syndromes and further contributes towards $7 p 22$ duplication being a recognizable dysmorphic syndrome.
\end{abstract}

Keywords: Chromosome 7 duplication; 7 p22.1 microduplication; Developmental delay; Craniofacial abnormalities; Autoimmune inflammatory arthritis; Skeletal abnormalities; Systemic lupus erythematosus

\section{Introduction}

Chromosome 7 duplication of various sizes and position has been described in the literature [1]. While most are associated with phenotypical features and developmental delay, a few case reports have suggested associated anomalies such as cardiac abnormalities, skeletal abnormalities and gastrointestinal and genital defects [2].

Previously cases of $7 \mathrm{p} 22.1$ microduplication with a size of $1 \mathrm{Mb}$ and 1.7 $\mathrm{Mb}$ have been reported showing similar phenotypical features including prominent forehead, anteverted nares, ocular hypertelorism and language delay [3,4]. Herein, we describe a third child with similar features duplication within chromosome 7 p22.1 found to have Systemic Lupus Erythematosus (SLE) and associated autoimmune arthritis. SLE is a severe inflammatory disease process, which is characterised by the dysfunction of dendritic cells, T cells, B cells, and the production of antinuclear antibodies [5].

We propose copy number variations (CNV) within the loci of chromosome 7 which contain the actin beta gene (ACTB) (OMIM\#102630) may lead to dysregulation of actin cytoskeleton function which is required for $\mathrm{T}$ cell and $\mathrm{B}$ cell function. This in turn may produce an increased susceptibility to autoimmune disease such as SLE.

\section{Clinical Report}

This 8 year-old girl was born into a non-consanguineous family with 4 other healthy children. Antenatal scan at 20 weeks gestation demonstrated short humeral and femoral lengths. She was born at term via vaginal delivery with a weight of $4.038 \mathrm{~kg}$.
She presented to a regional paediatric clinic at 18 months of age with concerns of speech and gross motor delay. At this stage investigations performed included karyotype, metabolic screen and thyroid function test all of which were normal. She was subsequently lost to follow-up, but represented at 7 years of age with learning difficulties, joint deformities and reduced mobility. She was noted to be $<3$ rd centile for her height and on the 3rd centile for her weight at $107.6 \mathrm{~cm}$ and $17.4 \mathrm{~kg}$ respectively. She had short stature with macrocephaly but no obvious mesomelia. She had a broad nasal bridge, coarse features, ocular hypertelorism, lowset and posterior rotated ears (Figure 1).

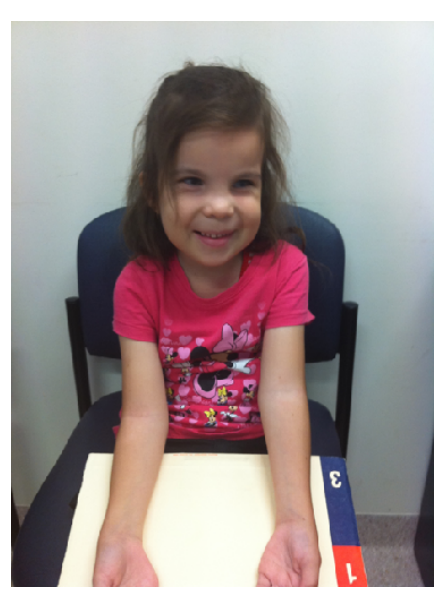

Figure 1: Demonstraing macrocephaly, broad nasal bridge, coarse features, and ocular hypertelorism.

She had deformity, fixed flexion contractions (with Boutonnière shape deformity) in her proximal interphalangeal joints (PIP) in her 
hands (Figure 2). Range of movement of both wrists reduced in all directions. Her knees were markedly enlarged with soft tissue swelling but normal range of movement. She demonstrated limited flexion and extension of her neck. Her skin and nail examination was normal. She has a soft systolic murmur which did not have a structural basis on echocardiography, and her respiratory and gastrointestinal examination was normal.

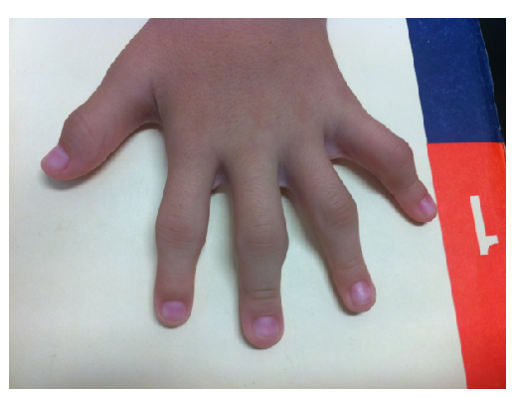

Figure 2: Left hand demonstrating deformity, fixed flexion contractions (with Boutonnière shape deformity) in the PIP joints.

Her skeletal survey revealed flexion deformity in the PIP with soft tissue swelling and distal osteopenia, and a J-shaped sella turcica. Tanner staging was stage one and she had normal genitalia. Ophthalmology examination revealed no evidence of uveitis with a normal vision.

Biochemical investigations which included blood count and film, basic liver and biochemistry, Creatine Kinase, Thyroid Function tests, urine metabolic screen, lysosomal white cell enzyme, carbohydrate deficient transferrin, and very long fatty acids, and urinary mucopolysaccharide electrophoresis screen returned as normal. At this time a work up for an autoimmune disease process didn't produce a clear diagnosis. She displayed a mild elevation in erythrocyte sedimentation rate, but complement studies ( 3 , $\mathrm{C} 4$, and $\mathrm{CH} 50$ ), rheumatoid factor, anti-Cardiolipin antibodies, anti-beta 2 glycoprotein 1 antibodies, antinuclear antibodies (ANA), IgD, and anti dsDNA were all normal. Repeating these investigations six months later demonstrated seroconversion with an elevated ANA: homogenous 640 (reference range $<40$ units) and anti-dsDNA 19 $\mathrm{IU} / \mathrm{ml}$ (reference range $<7$ ) confirming a SLE. Complement studies remained normal and a renal biopsy has not been performed to date.

A comparative genomic hybridization (CGH) array demonstrated a 1.4-1.9 Mb interstitial microduplication at the $7 \mathrm{p} 22.1$. The duplication region contains at least 20 known genes of which 2 have been described as disease associated ACTB (OMIM 102630) and postmeiotic segregation increased 2 (PMS2) (OMIM 600259) [3,4].

She was treated with high dose intravenous methyl prednisolone (30 $\mathrm{mg} / \mathrm{kg} / \mathrm{dose}$ ) as induction of treatment and commenced on maintenance therapy with methotrexate ( $15 \mathrm{mg} / \mathrm{sqm}$ once weekly) and hydroxycloroquine (3 $\mathrm{mg} / \mathrm{kg} /$ day) and her joint symptoms dramatically improved.

\section{Discussion}

With advancement in technology such as CGH arrays, there has been an explosion in the literature investigating the significance of deletions, duplications within each chromosome, leading to new microdeletion or microduplication syndromes [2,6-10].

Chromosome 7p22.1 abnormalities have been linked with developmental delay such as autism and skeletal abnormalities $[11,12]$. 2 children with similar phenotypical characteristics have been described and have chromosome 7 p22.1 microduplication at size of less than $2 \mathrm{MB}[3,4]$. Our child showed these similar phenotypical and cytogenetic features (Table 1). The facial gestural of these three patients suggest that $7 \mathrm{p} 22$ duplication is a clinically recognizable dysmorphic syndrome.

\begin{tabular}{|l|l|l|l|}
\hline Clinical Features & Patient 1 & Patient 2 & Patient 3 \\
\hline Macrocephaly & + & + & + \\
\hline Prominent Forehead & + & + & + \\
\hline Broad nasal bridge & + & + & + \\
\hline Anteverted nares & + & & \\
\hline Ocular hypertelorism & + & + & + \\
\hline Midface hypoplasia & & + & \\
\hline Retrognathia & & + & \\
\hline Thin Vermilian boarder & & + & + \\
\hline Low set ears & + & + & + \\
\hline Posteriorly rotatedears & + & + & + \\
\hline Coarse facial features & & & + \\
\hline Scoliosis & + & & \\
\hline j-shaped selia turcia & & + & + \\
\hline Short 5th toes & & + & + \\
\hline Tapered distal phalnges & & + & \\
\hline Distal osteopenia & & & + \\
\hline Joint contractures & & & \\
\hline $\begin{array}{l}\text { Deforming } \\
\text { arthrists }\end{array}$ & & & + \\
\hline SLE & & & \\
\hline Short stature & & & \\
\hline Intellectual impairement & & & + \\
\hline Speech and language delay & & & \\
\hline References & & & + \\
\hline
\end{tabular}

Table 1: Phenotypical features of children with Chromosome 7p22.1 microduplication and images for our case. Reference patient 1 [3], reference patient 2 [4].

Our case is the first reported patient with $7 \mathrm{p} 22$ duplication to demonstrate autoimmune arthritis and SLE, which expands the clinical phenotype associated with this rare copy number variation. There are well-documented links between autoimmunity and specific chromosomal microdeletion phenotypes, e.g. 22q11 deletion, $5 \mathrm{q}$ deletion and 18p deletion [13-15]. Some of these studies suggest that 
an immune dysregulation via a $\mathrm{T}$ cell mediated process may occur secondary to their specific microdeletion [15].

The most likely explanation for our patient developing an autoimmune disease is a direct result of her copy number variation $(\mathrm{CNV})$ at $7 \mathrm{p} 22.1$. CNV cause alterations in gene expression due to downstream attenuation of the gene function when the presence of variable copies of the entire gene is replicated $[6,16]$. In inbred lupusprone mouse strains that are Fas deficient, susceptible loci within centromeric region of chromosome 7 have been identified to cause SLE [17]. A wide range of genetic and epigenetic factors have identified across numerous chromosomal loci that can contribute towards the development of SLE [5]. Examples include genes associated with macrophage activation, cytokine signalling, and the actin cytoskeleton (Pearl 2010) [5,18-21].

Cronins are genes which control the disassembly of actin cytoskeleton which in turn modulates $\mathrm{T}$ cell activation playing a role in the pathogenesis of SLE [22,23]. Deregulation of T and B cell function has been shown to be linked to SLE $[24,25]$. $\alpha$-Actin has emerged as a major auto-antigen target for anit-dsDNA in the pathogenesis of SLE [26]. The ACTB gene (OMIM\#102630), whose gene product is $\beta$-actin, maps to 7 p22.1 and is within the duplicated region of our patient. Further support for the role of aberrant actin cytoskeleton function creating auto immune disease is the Wiskott-Aldrich Syndrome (OMIM 301000), which is caused by pathogenic mutations in the actin regulator (WASp protein) [27].

\section{Conclusion}

In summary, we describe the third known case of $7 \mathrm{p} 22.1$ microduplication and postulate that the facial features are suggestive of a recognizable dysmorphic syndrome and one associated with autoimmune disease. We postulate that $\mathrm{CNV}$ associated with the ACTB gene maybe contributory to the development of SLE and that all patients with 7 p22.1 microdeletion should undergo joint surveillance in the clinical setting.

\section{References}

1. Papadopoulou E, Sifakis S, Sarri C, Gyftodimou J, Liehr T, et al. (2006) A report of pure $7 \mathrm{p}$ duplication syndrome and review of the literature. Am J Med Genet A 140: 2802-2806.

2. Reish O, Berry SA, Dewald G, King RA (1996) Duplication of 7p: further delineation of the phenotype and restriction of the critical region to the distal part of the short arm. Am J Med Genet 61: 21-25.

3. Chui JV, Weisfeld-Adams JD, Tepperberg J, Mehta L (2011) Clinical and molecular characterization of chromosome 7 p22.1 microduplication detected by array CGH. Am J Med Genet A 155A: 2508-2511.

4. Preiksaitiene E, Kasnauskiene J, Ciuladaite Z, Tumiene B, Patsalis PC, et al. (2012) Clinical and molecular characterization of a second case of 7p22.1 microduplication. Am J Med Genet A 158A: 1200-1203.

5. Perl A (2010) Pathogenic mechanisms in systemic lupus erythematosus. Autoimmunity 43: 1-6.

6. Wain LV, Armour JA, Tobin MD (2009) Genomic copy number variation, human health, and disease. Lancet 374: 340-350.

7. Watson CT, Marques-Bonet T, Sharp AJ, Mefford HC (2014) The genetics of microdeletion and microduplication syndromes: an update. Annu Rev Genomics Hum Genet 15: 215-244.
8. Weise A, Mrasek K, Klein E, Mulatinho M, Llerena JC Jr, et al. (2012) Microdeletion and microduplication syndromes. J Histochem Cytochem 60: $346-358$

9. Nevado J, Mergener R, Palomares-Bralo M, Souza KR, Vallespín E, et al. (2014) New microdeletion and microduplication syndromes: A comprehensive review. Genet Mol Biol 37: 210-219.

10. Zahed L, Pramparo T, Farra C, Mikati M, Zuffardi O (2007) A patient with duplication (7)(p22.1pter) characterized by array-CGH. Am J Med Genet A 143A: 168-171.

11. Bayou N, Belhadj A, Daoud H, Briault S, Helayem MB, et al. (2010) Exploring the 7 p22.1 chromosome as a candidate region for autism. J Biomed Biotechnol 2010: 423894.

12. Vergult S, Hoogeboom AJ, Bijlsma EK, Sante T, Klopocki E, et al. (2013) Complex genetics of radial ray deficiencies: screening of a cohort of 54 patients. Genet Med 15: 195-202.

13. Pinheiro RF, Silva MR, Chauffaille Mde L (2006) The 5q-syndrome and autoimmune phenomena: report of three cases. Leuk Res 30: 507-510.

14. Turleau C (2008) Monosomy 18p. Orphanet J Rare Dis 3: 4.

15. Verloes A, Curry C, Jamar M, Herens C, O'Lague P, et al. (1998) Juvenile rheumatoid arthritis and $\operatorname{del}(22 \mathrm{q} 11)$ syndrome: a non-random association. J Med Genet 35: 943-947.

16. Yu B, Guan M, Peng Y, Shao Y, Zhang C, et al. (2011) Copy number variations of interleukin-17F, interleukin-21, and interleukin-22 are associated with systemic lupus erythematosus. Arthritis Rheum 63: 3487-3492.

17. Kong PL, Morel L, Croker BP, Craft J (2004) The centromeric region of chromosome 7 from MRL mice (Lmb3) is an epistatic modifier of Fas for autoimmune disease expression. J Immunol 172: 2785-2794.

18. Ahmad YA, Bruce IN (2001) Genetic epidemiology: systemic lupus erythematosus. Arthritis Res 3: 331-336.

19. Crispín JC, Liossis SN, Kis-Toth K, Lieberman LA, Kyttaris VC, et al. (2010) Pathogenesis of human systemic lupus erythematosus: recent advances. Trends Mol Med 16: 47-57.

20. Hedrich CM, Tsokos GC (2011) Epigenetic mechanisms in systemic lupus erythematosus and other autoimmune diseases. Trends Mol Med 17: 714-724.

21. Tiffin N, Adeyemo A, Okpechi I (2013) A diverse array of genetic factors contribute to the pathogenesis of systemic lupus erythematosus. Orphanet J Rare Dis 8: 2 .

22. Wickramarachchi DC, Theofilopoulos AN, Kono DH (2010) Immune pathology associated with altered actin cytoskeleton regulation. Autoimmunity 43: 64-75.

23. Haraldsson MK, Louis-Dit-Sully CA, Lawson BR, Sternik G, SantiagoRaber ML, et al. (2008) The lupus-related Lmb3 locus contains a diseasesuppressing Coronin-1A gene mutation. Immunity 28: 40-51.

24. Barda-Saad M, Braiman A, Titerence R, Bunnell SC, Barr VA, et al (2005) Dynamic molecular interactions linking the $\mathrm{T}$ cell antigen receptor to the actin cytoskeleton. Nat Immunol 6: 80-89.

25. Roybal KT, Sinai P, Verkade P, Murphy RF, Wülfing C (2013) The actindriven spatiotemporal organization of $\mathrm{T}$-cell signaling at the system scale. Immunol Rev 256: 133-147.

26. Mageed RA, Zack DJ (2002) Cross-reactivity and pathogenicity of antiDNA autoantibodies in systemic lupus erythematosus. Lupus 11: 783-786.

27. Zhang J, Dong B, Siminovitch KA (2009) Contributions of WiskottAldrich syndrome family cytoskeletal regulatory adapters to immune regulation. Immunol Rev 232: 175-194. 